\title{
Diagnosis of Amyloidosis: A Survey of Current Awareness and Clinical Challenges Among Cardiologists in Switzerland
}

Dennis Mircsof

Received: November 25, 2019 / Published online: January 20, 2020

(C) The Author(s) 2020

\section{ABSTRACT}

Introduction: Transthyretin amyloidosis (ATTR) is a progressive disease in which amyloid fibril deposition disrupts tissue structure and organ function. Many patients with ATTR present with cardiac involvement; recent studies indicate that ATTR prevalence is higher than expected in patients with certain heart conditions. Although long delays to diagnosis are common, recent treatment advances have made timely diagnosis critical to ensure appropriate patient management. Despite clinical guideline updates, it remains unclear how these are being implemented in routine patient care.

Methods: We performed a survey of practicing cardiologists in Switzerland to assess their knowledge of ATTR and current clinical practice.

Results: Overall, 72 cardiologists completed the questionnaire in a face-to-face interview $(n=16)$ or online $(n=56)$. Key findings

Enhanced Digital Features To view enhanced digital features for this article go to https://doi.org/10.6084/ m9.figshare.11407326.

Electronic supplementary material The online version of this article (https://doi.org/10.1007/s40119019-00160-8) contains supplementary material, which is available to authorized users.

D. Mircsof $(\bowtie)$

Pfizer AG, Zurich, Switzerland

e-mail: dennis.mircsof@pfizer.com highlighted wide variation in cardiologists' knowledge about the diagnostic tests required for a differential diagnosis of ATTR. In particular, many cardiologists lacked familiarity with radiolabeled bone scintigraphy, an important non-invasive test that is part of the diagnostic algorithm for ATTR. Another challenge in diagnosing amyloidosis appears to be general awareness of ATTR among cardiologists.

Conclusions: Survey results highlight that cardiologists in Switzerland would benefit from information on the latest advances in ATTR to support them in screening heart failure patients and ensure that patients benefit from treatment advances.

Keywords: Amyloidosis; Cardiac; Cardiologist; Switzerland; Transthyretin 


\section{Key Summary Points}

Why carry out this study?

Cardiac amyloidosis is a progressive disease in which insoluble amyloid fibrils are deposited in cardiac tissue, preventing normal cardiac function.

There have been recent advances in treatments that can delay or prevent the accumulation of amyloid. However, misdiagnosis or delayed diagnosis is still common.

This survey was done to assess the knowledge of cardiac amyloidosis and its diagnosis among practicing cardiologists in Switzerland.

What was learned from the study?

One of the biggest challenges in diagnosing amyloidosis is awareness among cardiologists.

In addition, many cardiologists lack familiarity with radiolabeled bone scintigraphy, an important non-invasive diagnostic test in cardiac amyloidosis.

Cardiologists in Switzerland could benefit from additional information on the latest advances in the diagnosis of cardiac amyloidosis to facilitate appropriate screening of heart failure patients for this progressive disease.

\section{INTRODUCTION}

Cardiac amyloidosis is a progressive disease in which insoluble amyloid fibrils are deposited outside the cells in cardiac tissue, affecting tissue structure and preventing normal cardiac function [1]. Five different proteins cause cardiac amyloidosis, one of which is transthyretin (TTR), which causes TTR amyloidosis (ATTR) and is associated with heart failure [1].
Variant or hereditary ATTR (hATTR) occurs in $<1 / 100,000$ people, with considerable geographic variation [1]. Wild-type ATTR (wtATTR) is more common than hATTR, although its exact prevalence remains to be established: it has historically been considered rare, but recent studies indicate that it may be more common than previously thought [1]. One of the studies that initiated this shift in opinion was a populationbased autopsy study in Finland $(n=256)$, in which systemic amyloidosis was identified in 25\% of deaths in people aged $\geq 85$ years old [2]. Other studies point to a more specific population in which ATTR is more common than in the general population: many patients with wtATTR present with cardiac involvement. For example, in one prospective study, 120 patients $\geq 60$ years old who had heart failure with preserved ejection fraction and left ventricular hypertrophy (enddiastolic wall thickness $\geq 12 \mathrm{~mm}$ ) were prospectively screened using bone scintigraphy; 13\% had wtATTR [3]. In a different patient population, a prospective cardiac imaging study of 151 patients (mean age 84 years) with severe symptomatic aortic stenosis who had just undergone transaortic valve implantation (TAVI), showed that $16 \%$ had ATTR [4]. These findings were supported by a study of 101 patients (mean age 86 years) with severe aortic stenosis who had not yet undergone TAVI; the rate of ATTR was $14 \%$ [5]. Another retrospective study reported cardiac amyloidosis in $8 \%$ of 113 patients with moderate or severe aortic stenosis. Although the patient numbers in this study were low, patients with cardiac amyloidosis had significantly higher all-cause mortality at 1 year than patients with isolated aortic stenosis, regardless of whether or not they underwent aortic valve replacement [6]. These studies highlight the prevalence of 'hidden' ATTR, raising important questions about how ATTR affects clinical outcomes after TAVI, and how these patients can be identified and treated in the future.

Owing to its rarity, most general cardiologists lack clinical experience in the diagnosis and treatment of ATTR cardiomyopathy (ATTR-CM). Misdiagnosis or delayed diagnosis is common. Furthermore, despite advances in the clinical development of novel treatments, some cardiologists retain the belief that the disease cannot be 
treated, and consequently are reluctant to carry out invasive tests to obtain a diagnosis. As described above, the number of patients being diagnosed with ATTR amyloidosis has increased in recent years. A number of factors likely contribute to this pattern: an ageing population may contribute to a higher prevalence of ATTR amyloidosis; improved diagnostic tools such as bone scintigraphy allow its clinical identification; and the recent approval of therapies that can delay or prevent the accumulation of amyloid, making diagnosis and classification of the underlying protein more important $[7,8]$. Early diagnosis is now critical to ensure timely and appropriate patient management strategies.

Despite the increase in diagnoses, the delay to diagnosis remains substantial. In one prospective UK study including 534 patients with ATTR, the median time from first presentation with cardiac symptoms to diagnosis was 39 months (interquartile range [IQR] 8-78 months) for wtATTR and 25 months (IQR 4-60 months) for hATTR. Of patients with wild-type disease, $42 \%$ waited over 4 years for a diagnosis [9]. By the time they were diagnosed, these patients $(n=534)$ had completed a median of 17 hospital visits, including three admissions for inpatient care [9]. A similar delay has been reported in a retrospective study in the US in which median time to ATTR amyloidosis diagnosis $(n=52)$ was 34 months (IQR 15-72 months). Some of the factors that were significantly associated with a longer delay to diagnosis were a medical history of carpal tunnel syndrome, having a pacemaker, being younger at symptom onset, and having neuropathy as one of the presenting symptoms [10].

Specific challenges in diagnosing ATTR-CM include its phenotypic and genetic heterogeneity (being a systemic disease, involvement of cardiac tissue alone is infrequent); lack of specialist and specific diagnostic tests; the requirement for organ tissue for histologic analysis to obtain a definitive diagnosis; and the hypertrophic phenotype, which can lead to misdiagnosis [8]. The problem of phenotypic heterogeneity, even with respect to the cardiac presentation of ATTR amyloidosis, is underlined by a recent, cohort study of 108 patients with wtATTR. Extensive variation was reported in patients' clinical, electrocardiographic (ECG), and echocardiographic (ECHO) features. It appears that there is no reliable 'classic phenotype': one-third of patients did not present with symptoms of heart failure, and only $22 \%$ of patients had low-voltage electrocardiogram, which has previously been considered a key sign of cardiac amyloidosis. Hypertensive heart disease was the most common previous misdiagnosis [11]. Patients with hATTR can also be difficult to diagnose: cardiologists often need to proactively enquire about family history, as this information may not be offered of patients' own accord [8].

Some of the challenges in ATTR-CM are being addressed: for example, new diagnostic tools obviate the need for organ tissue to support histologic diagnosis in many cases. New treatments for ATTR amyloidosis have been approved in some countries and clinical development is ongoing. Although clinical guidelines are being updated to reflect these advances, it is not yet clear to what extent they are being implemented in routine clinical practice. In order to assess current clinical practice in Switzerland, we carried out a survey of practicing cardiologists in clinics across Switzerland. Survey objectives were as follows:

- Assess current awareness and knowledge of amyloidosis, particularly ATTR-CM.

- Obtain data on the procedures used to diagnose heart failure, and make a differential diagnosis in patients with heart failure to identify cardiomyopathy associated with transthyretin.

\section{METHODS}

A survey was conducted among practicing cardiologists based on 50 academic and non-academic centers in Switzerland. It was conducted either face-to-face (16 participants at 16 centers) or online (56 participants at 34 centers). Questions asked in the survey were developed in consultation with a cardiologist advisor and reviewed by a market research expert before implementation. The same questions were used in both settings, with some additional questions in face-to-face interviews (28 questions) compared with online (24 questions). Questions covered participants' clinical experience and 
Table 1 Number of patients treated by surveyed cardiologists in the past year

\begin{tabular}{|c|c|c|c|c|c|}
\hline & \multicolumn{2}{|l|}{ Heart failure } & \multicolumn{2}{|c|}{ Heart failure with preserved ejection fraction } & \multirow{2}{*}{$\begin{array}{l}\text { TAVI } \\
\text { Treated }\end{array}$} \\
\hline & Diagnosed & Treated & Diagnosed & Treated & \\
\hline \multicolumn{6}{|c|}{ Interview participants $(n=16)$} \\
\hline Median (range) & $50(8-500)$ & $200(25-600)$ & $20(5-300)$ & $65(10-300)$ & $6(0-50)$ \\
\hline \multicolumn{6}{|c|}{ Online participants $(n=56)$} \\
\hline Median (range) & $90(5-1500)$ & $135(10-2000)$ & $30(2-1000)$ & $60(2-1500)$ & $10(0-200)$ \\
\hline
\end{tabular}

$T A V I$ transcatheter aortic valve implantation

everyday clinical practice, requiring a mix of open and multiple-choice answers. Copies of the online and face-to-face questionnaires are provided in the Supplementary Materials.

A predefined list of cardiologists was invited to participate in the online questionnaire via regular mail, with follow-up reminders sent by e-mail to those for whom e-mail addresses were known. All cardiologists who were contacted were provided with a unique access code that could only be used once, to prevent multiple entries of the online questionnaire by one individual. All participants were required to complete the online survey between January and March 2019. Face-to-face interviews were 30-45 min long and took place in the participants' place of work between January and March 2019.

Survey participation was voluntary and anonymous, and in compliance with local data protection laws. Additional ethical approval was not required, as this was a clinical practice survey. In both settings, participants received reimbursement for their time: CHF 100 for online completion and CHF 150 for a face-toface interview. Data were analyzed using descriptive statistics and are presented as percentages for nominal variables.

\section{RESULTS}

\section{Survey Participants}

Of an estimated 1061 practicing cardiologists in Switzerland, 800-those for whom contact details were available-were invited to participate in the survey. Of these, 72 completed the
Table 2 Number of patients with amyloidosis managed by surveyed cardiologists in the past year

\begin{tabular}{lll}
\hline ATTR & $\begin{array}{l}\text { Light-chain } \\
\text { amyloidosis }\end{array}$ & $\begin{array}{l}\text { Amyloid A } \\
\text { amyloidosis }\end{array}$ \\
\hline Interview participants $(n=16)$ & \\
Median 2 & 1 & 0 \\
Online participants $(n=46)$ & 2 \\
Median 2 & 2 &
\end{tabular}

ATTR transthyretin amyloidosis

questionnaire either in a face-to-face interview $(n=16)$ or online $(n=56)$. Of the 16 general cardiologists who were interviewed face-to-face, two also described their role as 'heart failure specialists', two as 'rhythmologists', and two as 'interventional cardiologists'. There were no amyloidosis specialists among this group of participants. These cardiologists treated a median of 50 patients per week (range, 30-125).

Of the 72 survey respondents, 56 cardiologists completed the survey online. One described their role as an amyloidosis specialist and 11 described themselves as heart failure specialists; a further eight described their area of specialism as 'other'. These cardiologists treated a median of 40 patients per week (range, 10-120).

The patient population treated by each subgroup of participants in the past year is shown in Table 1. In both subgroups, cardiologists managed a median of two patients with ATTR per year (Table 2). 
Table 3 Features of chronic heart failure that would cause cardiologists to consider a possible diagnosis of ATTR

\begin{tabular}{|c|c|c|}
\hline & $\begin{array}{l}\text { Percentage of } \\
\text { interview } \\
\text { participants } \\
(n=16)\end{array}$ & $\begin{array}{l}\text { Percentage } \\
\text { of online } \\
\text { participants } \\
(n=54)\end{array}$ \\
\hline $\begin{array}{l}\text { Preserved or reduced } \\
\text { ejection fraction, or } \\
\text { both }\end{array}$ & 56 & 89 \\
\hline $\begin{array}{l}\text { Left ventricular } \\
\text { hypertrophy } \\
\text { without } \\
\text { simultaneous high } \\
\text { blood pressure }\end{array}$ & 31 & 83 \\
\hline $\begin{array}{l}\text { Heart failure } \\
\text { symptoms with } \\
\text { poor response to } \\
\text { standard treatment }\end{array}$ & 63 & 63 \\
\hline $\begin{array}{l}\text { Medical history of } \\
\text { bilateral carpal } \\
\text { tunnel syndrome }\end{array}$ & 38 & 56 \\
\hline $\begin{array}{l}\text { Neuropathy with } \\
\text { paraesthesia/ } \\
\text { sensory impairment }\end{array}$ & 50 & 59 \\
\hline $\begin{array}{l}\text { Increased troponin in } \\
\text { the absence of } \\
\text { acute coronary } \\
\text { syndrome }\end{array}$ & 13 & 46 \\
\hline $\begin{array}{l}\text { Family history of } \\
\text { heart failure }\end{array}$ & 25 & 48 \\
\hline Hypertrophy & 25 & Not listed \\
\hline Low-voltage ECG & 88 & 76 \\
\hline $\begin{array}{l}\text { ECG (Pseudo-Q- } \\
\text { wave) }\end{array}$ & Not listed & 26 \\
\hline $\begin{array}{l}\text { Lumbar spinal } \\
\text { stenosis }\end{array}$ & Not listed & 13 \\
\hline
\end{tabular}

$E C G$ electrocardiogram

\section{ATTR Amyloidosis: Differential Diagnosis and Clinical Expertise}

Features of heart failure that would cause the surveyed cardiologists to consider a possible diagnosis of ATTR amyloidosis are shown in Table 3.

Of 56 participants who completed the survey online, only $15 \%$ rated their expertise of differentiating ATTR amyloidosis from other forms of amyloidosis as 'high', whereas $40 \%$ of participants rated their expertise as 'low', a further $40 \%$ as 'basic' and 5\% stated that they had no expertise in this area. In the event of treating patients with suspected ATTR amyloidosis, 64\% of online participants said they would refer these patients to a specialist, whereas only $35 \%$ stated that they could treat the patients themselves. A further $2 \%$ stated that they would not refer these patients as they did not see the need for further examination. Of the 16 interview participants, $47 \%$ would refer a patient with ATTR amyloidosis to a specialist center for treatment, and $40 \%$ would treat the patient themselves. A further $13 \%$ stated that they would not refer a patient with ATTR amyloidosis because there is currently no available treatment.

\section{Differential Diagnosis of Amyloidosis in Patients with Heart Failure}

Diagnostic tests used in patients with suspected heart failure are shown in Fig. 1. There was a notable difference between the interview and online groups in use of bone scintigraphy (31 vs. $1 \%$, respectively), biopsy (38 vs. $1 \%$, respectively), and MRI (88 vs. 30\%, respectively). Diagnostic tests for amyloidosis considered by survey participants are shown in Table 4 . The most common tests (ECHO, serum protein electrophoresis, free light chain tests) were similar between the interview and online groups. Bone scintigraphy was listed by $63 \%$ of online participants but was not listed in the interview group. 


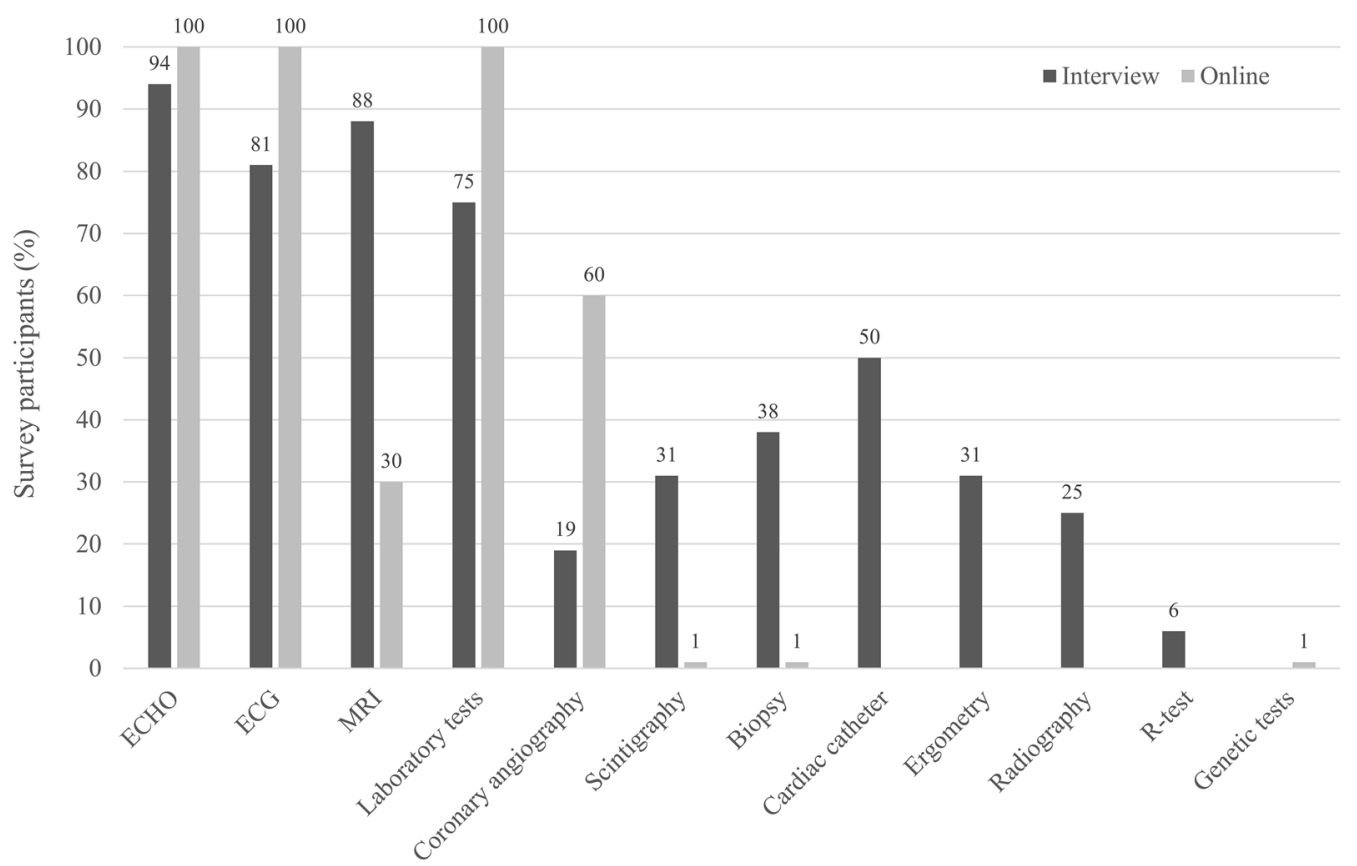

Fig. 1 Tests used to diagnose patients with suspected heart failure, grouped by face-to-face interview and online participants. 'Laboratory' includes measurement of NT-

\section{Subgroup of Cardiologists Who Completed the Survey Face-To-Face: Diagnosing Cardiac Amyloidosis}

Cardiologists who completed the survey face-toface $(n=16)$ answered questions about their knowledge of amyloidosis. When asked to list typical features of amyloidosis, answers were unspecific, with the most common being neurological disorders $(n=4)$, dyspnea $(n=4)$, specific MRI reading $(n=3)$, edema $(n=3)$, and renal insufficiency $(n=3)$. In this group of respondents, the best-known features of an ECHO or ECG that indicate possible cardiac amyloidosis were low-voltage ECG (88\%), left ventricular hypertrophy (75\%), and cardiac sparkling (56\%). The majority of these cardiologists $(94 \%)$ had at some point suspected that at least one of their patients had cardiac amyloidosis. If cardiac amyloidosis was suspected, 94\% would arrange a biopsy, nearly 69\% would arrange an ECHO, 56\% would arrange an MRI and $44 \%$ would arrange for bone scintigraphy as part of further investigations. For the final diagnosis of cardiac amyloidosis, most pro BNP and of troponin. $E C H O$ echocardiogram, $E C G$ electrocardiogram

respondents would use a biopsy (69\%), with other options being less common ('a combination of several diagnostic tests' by $31 \%$ of cardiologists and bone scintigraphy by $25 \%$ ). One participant stated that they would not carry out any confirmatory tests at all, as there is no treatment available.

\section{Subgroup of Cardiologists Who Completed the Survey Face-To-Face: Qualitative Findings}

The perceptions held by this group of cardiologists $(n=16)$ about the various possible diagnostic tests for cardiac amyloidosis are shown in Table 5.

Participants reported that the most frequent time period between the first symptoms of heart failure and diagnosis of cardiac amyloidosis was 2-3 years (reported by $50 \%$ of cardiologists). With regard to challenges in diagnosing cardiac amyloidosis, the most common obstacle reported by cardiologists was thinking of cardiac amyloidosis at the right time. The second most common challenge was lack of a simple 
Table 4 Diagnostic tests considered by cardiologists for patients with a possible diagnosis of amyloidosis

\begin{tabular}{lll}
\hline & $\begin{array}{l}\text { Percentage of } \\
\text { interview } \\
\text { participants } \\
(\boldsymbol{n}=\mathbf{1 6})\end{array}$ & $\begin{array}{l}\text { Percentage } \\
\text { of online } \\
\text { participants } \\
(\boldsymbol{n}=\mathbf{5 4})\end{array}$ \\
\hline $\begin{array}{l}\text { Echocardiogram } \\
\begin{array}{l}\text { Serum protein } \\
\text { electrophoresis }\end{array}\end{array}$ & 100 & 98 \\
$\begin{array}{l}\text { Non-cardiac tissue } \\
\text { biopsy }\end{array}$ & 82 & 83 \\
$\begin{array}{l}\text { Free light chain tests } \\
\text { Urine protein }\end{array}$ & 81 & 54 \\
$\quad$ electrophoresis & 75 & 76 \\
$\begin{array}{l}\text { Heart biopsy } \\
\text { Serum }\end{array}$ & 69 & 61 \\
immunoglobulin test & 64 & 57 \\
Other blood-based & 44 & 9 \\
tests & & 63 \\
Immunohistochemistry & 31 & Not listed \\
Genetic tests & 25 & 46 \\
Bone scintigraphy & Not listed & 63 \\
Mass spectrometry & Not listed & 6 \\
\hline
\end{tabular}

diagnostic test/difficulty in using the right diagnostic tools; other common challenges were the unspecific symptoms at presentation, the fact that there is relatively little known about cardiac amyloidosis, and the lack of currently available treatments.

Cardiologists reported that cardiac amyloidosis is most likely to be diagnosed in younger patients with unexplained heart failure who have a family history of cardiac amyloidosis, and exhibit hypertrophy without hypertension. Generally, other organs are already affected in these patients. Cardiac amyloidosis is most likely to be overlooked in patients $>60$ years
Table 5 Perception of interview participants $(n=16)$ of the various diagnostic tests for cardiac amyloidosis

\begin{tabular}{|c|c|c|}
\hline Diagnostic test & Advantages & Disadvantages \\
\hline Peripheral biopsy & $\begin{array}{l}\text { Simple, cost- } \\
\text { effective, few } \\
\text { complications, } \\
\text { very high } \\
\text { specificity }\end{array}$ & $\begin{array}{l}\text { Invasive, risk of } \\
\text { complications, } \\
\text { only safe with } \\
\mathrm{AL} \text {, otherwise } \\
\text { only } 50 \% \\
\text { hit rate }\end{array}$ \\
\hline Myocardial biopsy & $\begin{array}{l}\text { Very high } \\
\text { sensitivity and } \\
\text { specificity, high } \\
\text { informative } \\
\text { value }\end{array}$ & $\begin{array}{l}\text { Invasive, higher } \\
\text { risk of } \\
\text { complications, } \\
\text { sampling errors }\end{array}$ \\
\hline Immune fixation & $\begin{array}{l}\text { Simple, cost- } \\
\text { effective, few } \\
\text { complications }\end{array}$ & \\
\hline Bone scintigraphy & $\begin{array}{l}\text { Non-invasive, } \\
\text { very high } \\
\text { sensitivity and } \\
\text { specificity, } \\
\text { reproducibility, } \\
\text { cost-effective }\end{array}$ & $\begin{array}{l}\text { Lack of } \\
\text { experience, still } \\
\text { unclear } \\
\text { evidence, only } \\
\text { for ATTR- } \\
\text { CM, radiation } \\
\text { exposure }\end{array}$ \\
\hline MRI & $\begin{array}{l}\text { Good availability, } \\
\text { medium to high } \\
\text { sensitivity and } \\
\text { specificity }\end{array}$ & $\begin{array}{l}\text { Expensive, } \\
\text { claustrophobia } \\
\text { in } 10-20 \% \text { of } \\
\text { patients, } \\
\text { contrast agent } \\
\text { for renal } \\
\text { insufficiency }\end{array}$ \\
\hline Electrocardiogram & $\begin{array}{l}\text { Very good } \\
\text { availability }\end{array}$ & $\begin{array}{l}\text { Low sensitivity } \\
\text { and specificity, } \\
\text { false-positive } \\
\text { results, e.g., in } \\
\text { pericardial } \\
\text { effusion and } \\
\text { obesity }\end{array}$ \\
\hline
\end{tabular}


Table 5 continued

\begin{tabular}{lcc}
\hline Diagnostic test & Advantages & Disadvantages \\
\hline Echocardiogram & $\begin{array}{c}\text { Very good } \\
\text { availability, } \\
\text { cost-effective, } \\
\text { high diagnostic } \\
\text { value }\end{array}$ & $\begin{array}{c}\text { Low sensitivity } \\
\text { and specificity, } \\
\text { false- positive } \\
\text { results, e.g., in } \\
\text { hypertonic }\end{array}$ \\
& & patients \\
Cardiac catheters & $\begin{array}{c}\text { Immediate } \\
\text { intervention }\end{array}$ & Invasive, risk of \\
& possible if & \\
necessary & \\
Genetic tests & & Low availability, \\
& & expensive \\
\hline
\end{tabular}

$A L$ amyloid light-chain, ATTR-CM transthyretin amyloidosis associated cardiomyopathy

old who have other cardiac diseases or risk factors, including hypertension with accompanying hypertrophy, coronary artery disease, and hypertrophic cardiomyopathy. It is also widely overlooked in patients $<50$ years old who have an underlying hematological illness such as multiple myeloma, and in patients without hypertrophy.

In contrast to the findings above, these cardiologists reported that in their clinical experience, most patients diagnosed with ATTR amyloidosis have been on average $>70$ years old, with the majority having New York Heart Association (NYHA) Stage III heart failure.

\section{DISCUSSION}

There was wide variation in cardiologists' knowledge about amyloidosis and in the diagnostic tests that they would carry out during a differential diagnosis of ATTR-CM.

Many cardiologists in the survey were not very familiar with radiolabeled bone scintigraphy, with some citing lack of experience and unclear evidence as disadvantages. However, bone scintigraphy using technetium-labeled radiotracers has been shown to have high sensitivity and specificity for ATTR-CM [12]. Bone scintigraphy has been included as a screening tool for ATTR-CM in the 2016 European Society of Cardiology guidelines for the treatment of heart failure [13] and in a recently published consensus statement from the Heart Failure Association of the European Society of Cardiology [14]. In a study including 1217 evaluable patients being assessed for amyloidosis-of which 857 had histologically proven amyloid-the myocardial radiotracer uptake seen in bone scintigraphy images had $>99 \%$ sensitivity and $86 \%$ specificity for cardiac ATTR [15]. Combining bone scintigraphy with a test showing absence of monoclonal protein (e.g., using serum or urine immunofixation or a free light chain assay) increases the diagnostic specificity for ATTR further. These tests now form the basis of a diagnostic algorithm designed to minimize invasive procedures in cardiac amyloidosis [15]. Some uncertainties remain that have been accommodated in the algorithm: while a high myocardial tracer uptake (grades 2-3) is sensitive for wtATTR, mild uptake could indicate asymptomatic or early cardiac involvement in hATTR or immunoglobulin light-chain disease [8]. This is accommodated in the algorithm [15]. In addition, a recently published expert consensus describes the appropriate use of radionuclide imaging, among other imaging modalities, in the clinical evaluation of patients thought to have ATTR [16]. It is hoped that standardized methods and quantification of amyloid load will help improve clinical uptake further and support disease staging in future [17]. To achieve these aims, data collection is required, making widespread clinical use of scintigraphy all the more important. Another challenge for the future will be differentiating clinically significant from incidental amyloid deposits [9].

Interview respondents of our survey stated that the best-known features of an ECHO or ECG that indicate possible cardiac amyloidosis were low-voltage ECG (88\%), left ventricular hypertrophy $(75 \%)$, and cardiac sparkling (56\%). These replies do not entirely reflect the most recent evidence base, which has highlighted some common misconceptions about the diagnosis of cardiac amyloidosis. A low- 
voltage ECG in isolation is an insufficient observation on which to base a diagnosis of cardiac amyloidosis. This finding can occur in as few as one-fifth of patients with ATTR-CM. In addition, ECG voltage readings are unreliable in patients who have a pacemaker $[8,11]$. Another commonly held perception is that wtATTR is associated with increased ventricle wall thickness. However, a recent publication highlighted that normal ventricle wall thickness does not exclude the possibility of cardiac amyloidosis [11].

The survey highlighted that one of the biggest challenges in diagnosing amyloidosis is awareness among cardiologists. In general, respondents treated very few patients with ATTR (a median of two per year). This highlights that a high index of suspicion is required from cardiologists to diagnose ATTR-CM.

Although Switzerland is not included in the worldwide, longitudinal, observational Transthyretin Amyloidosis Outcomes Survey (THAOS) registry of patients with ATTR amyloidosis, in a recent sub-analysis of subjects from Western Europe $(n=1411$, of which 125 had wtATTR), data also highlight the key role of cardiologists in identifying and managing ATTR-CM. Patients with the cardiac phenotype already-exhibited symptoms of heart failure (68\% had NYHA stage II-IV) and a clinically meaningful increase in left ventricular wall thickness at diagnosis [18]. A similar lesson can be learnt from a cohort study of 198 patients with ATTR-CM in the US, in which elevated concentrations of B-type natriuretic peptide were significantly associated with mortality, emphasizing the need for careful cardiac management of these patients to prevent premature deterioration of their condition [19].

As already discussed, there are now indications that ATTR is not as rare as previously thought. In our survey, even those cardiologists who are aware of the condition and available treatments shared some concerns about administering new therapies to patients who are elderly and have multiple comorbidities. With progress made in the management of ATTR, and the fact that its prognosis differs from those of other cardiomyopathies (especially if other cardiac conditions are present), appropriate education and screening is now essential to optimize patient care.

In addition to diagnostic tests, cardiologists should be aware of the clinical indicators of ATTR-CM, which include: exercise intolerance [7]; carpal tunnel syndrome [20, 21]; lumbar spinal stenosis; atraumatic biceps tendon rupture; ascending bilateral sensory-motor polyneuropathy; dysautonomia, including orthostatic hypotension; eye involvement such as glaucoma or intravitreal deposition; and diagnosis of hypertrophic cardiomyopathy in patients $>60$ years old $[1,8]$. Clinical scenarios and 'red flags' that warrant screening for ATTR$\mathrm{CM}$ have been recently summarized elsewhere [22]. Finally, once a diagnosis of ATTR-CM has been made, cardiologists need to ensure that they have not missed any co-existing cardiac conditions.

This survey is a small survey designed to provide information on cardiology practice in Switzerland. There were a couple of internal inconsistencies within the results. The most notable was the marked difference between interview and online groups in considering the use of bone scintigraphy and biopsy in patients with suspected heart failure ( 31 vs. $1 \%$ and 38 vs. $1 \%$, respectively; Fig. 1 ). These data are inconsistent with those that describe diagnostic tests considered for patients with a possible diagnosis of ATTR-CM, in which responses between interview and online participants appear to be reversed: a high proportion of online participants considered bone scintigraphy, but no interview participants did (Fig. 1 versus Table 4). In another example, when asked specifically which ECG characteristics are indicative of amyloidosis, $75 \%$ of interview participants listed left ventricular hypertrophy without simultaneous high blood pressure, compared with only $31 \%$ of this group who listed the same as a feature of chronic heart failure associated with a possible diagnosis of ATTR. It is possible that these discrepancies arose because the mix of open-format and multiple-choice questions caused some confusion during interview about whether the question related to heart failure or ATTR-CM. This is supported by the fact that $38 \%$ of interview participants stated that they would consider a 
biopsy to diagnose patients with suspected heart failure, which is not standard practice. In addition, it is possible that interview participants did not mention things that they considered to be 'self-evident' in relation to certain open-format questions. The inclusion of open questions for certain topics would therefore be reconsidered in any future updates of the survey.

A major limitation of this study is that, despite the survey being sent out to approximately eight out of ten practicing cardiologists in Switzerland, only a small proportion of them (about 10\% of those contacted) participated in the study. This incomplete coverage of the target population could be associated with 'responder bias', i.e., results may not be entirely representative of all cardiologists in Switzerland. The results of the survey should be interpreted within this context. However, respondents were from a range of academic and non-academic institutes and were reasonably geographically diverse across the country.

\section{CONCLUSIONS}

Cardiologists in Switzerland could benefit from additional information on the latest advances in the diagnosis and management of ATTR-CM. This would support them in implementing improved screening of heart failure patients in Switzerland for ATTR-CM. In addition, this article highlights the need to establish a consistent, nationwide approach to the diagnosis and referral of patients with suspected ATTRCM in Switzerland. These measures would help ensure that patients benefit from advances in the management of this progressive disease.

\section{ACKNOWLEDGEMENTS}

The author would like to thank all survey participants.

Funding. This research and the journal's Rapid Service Fee was funded by Pfizer.
Medical Writing, Editorial and Other Assistance. Medical writing and editorial assistance were provided by Sam Kew (Synergy) and was supported by Pfizer AG. The author would like to thank Theo Kaeser (Fluentis $\mathrm{GmbH}$ ) for statistical analysis of the survey results. The survey was conducted by Fluentis GmBH and supported by Pfizer AG.

Authorship. All named authors meet the International Committee of Medical Journal Editors (ICMJE) criteria for authorship for this article, take responsibility for the integrity of the work as a whole, and have given their approval for this version to be published.

Disclosures. Dennis Mircsof is an employee of Pfizer.

Compliance with Ethics Guidelines. Survey participation was voluntary and anonymous, and in compliance with local data protection laws. Additional ethical approval was not required as this was a clinical practice survey.

Data Availability. The datasets generated during and/or analyzed during the current study are available from the corresponding author on reasonable request.

Open Access. This article is distributed under the terms of the Creative Commons Attribution-NonCommercial 4.0 International License (http://creativecommons.org/licenses/ by-nc/4.0/), which permits any non-commercial use, distribution, and reproduction in any medium, provided you give appropriate credit to the original author(s) and the source, provide a link to the Creative Commons license, and indicate if changes were made.

\section{REFERENCES}

1. Gonzalez-Lopez E, Lopez-Sainz A, Garcia-Pavia P. Diagnosis and treatment of transthyretin cardiac amyloidosis. Progress Hope. 2017;70(11):991-1004. 
2. Tanskanen M, Peuralinna T, Polvikoski T, Notkola IL, Sulkava R, Hardy J, et al. Senile systemic amyloidosis affects $25 \%$ of the very aged and associates with genetic variation in alpha2-macroglobulin and tau: a population-based autopsy study. Ann Med. 2008;40(3):232-9.

3. Gonzalez-Lopez E, Gallego-Delgado M, Guzzo-Merello G, de Haro-Del Moral FJ, Cobo-Marcos M, Robles $\mathrm{C}$, et al. Wild-type transthyretin amyloidosis as a cause of heart failure with preserved ejection fraction. Eur Heart J. 2015;36(38):2585-94.

4. Castano A, Narotsky DL, Hamid N, Khalique OK, Morgenstern R, DeLuca A, et al. Unveiling transthyretin cardiac amyloidosis and its predictors among elderly patients with severe aortic stenosis undergoing transcatheter aortic valve replacement. Eur Heart J. 2017;38(38):2879-87.

5. Scully PR, Treibel TA, Fontana M, Lloyd G, Mullen M, Pugliese F, et al. Prevalence of cardiac amyloidosis in patients referred for transcatheter aortic valve replacement. J Am Coll Cardiol. 2018;71(4): 463-4.

6. Cavalcante JL, Rijal S, Abdelkarim I, Althouse AD, Sharbaugh MS, Fridman Y, et al. Cardiac amyloidosis is prevalent in older patients with aortic stenosis and carries worse prognosis. J Cardiovasc Magn Reson. 2017;19(1):98.

7. Brunjes DL, Castano A, Clemons A, Rubin J, Maurer MS. Transthyretin cardiac amyloidosis in older Americans. J Card Fail. 2016;22(12):996-1003.

8. Rapezzi C, Lorenzini M, Longhi S, Milandri A, Gagliardi C, Bartolomei I, et al. Cardiac amyloidosis: the great pretender. Heart Fail Rev. 2015;20(2): $117-24$.

9. Lane T, Fontana M, Martinez-Naharro A, Quarta CC, Whelan CJ, Petrie A, et al. Natural history, quality of life, and outcome in cardiac transthyretin amyloidosis. Circulation. 2019;140(1):16-26.

10. Bishop E, Brown EE, Fajardo J, Barouch LA, Judge DP, Halushka MK. Seven factors predict a delayed diagnosis of cardiac amyloidosis. Amyloid. 2018;25(3):174-9.

11. Gonzalez-Lopez E, Gagliardi C, Dominguez F, Quarta CC, de Haro-Del Moral FJ, Milandri A, et al. Clinical characteristics of wild-type transthyretin cardiac amyloidosis: disproving myths. Eur Heart J. 2017;38(24):1895-904.

12. Treglia G, Glaudemans A, Bertagna F, Hazenberg BPC, Erba PA, Giubbini R, et al. Diagnostic accuracy of bone scintigraphy in the assessment of cardiac transthyretin-related amyloidosis: a bivariate meta- analysis. Eur J Nucl Med Mol Imaging. 2018;45(11): 1945-55.

13. Ponikowski P, Voors AA, Anker SD, Bueno H, Cleland JGF, Coats AJS, et al. 2016 ESC Guidelines for the diagnosis and treatment of acute and chronic heart failure: the Task Force for the diagnosis and treatment of acute and chronic heart failure of the European Society of Cardiology (ESC) developed with the special contribution of the Heart Failure Association (HFA) of the ESC. Eur Heart J. 2016;37(27):2129-200.

14. Seferovic PM, Ponikowski P, Anker SD, Bauersachs J, Chioncel O, Cleland JGF, et al. Clinical practice update on heart failure 2019: pharmacotherapy, procedures, devices and patient management. An expert consensus meeting report of The Heart Failure Association of the European Society of Cardiology. Eur J Heart Fail. 2019;21:1169-86.

15. Gillmore JD, Maurer MS, Falk RH, Merlini G, Damy $\mathrm{T}$, Dispenzieri A, et al. Nonbiopsy diagnosis of cardiac transthyretin amyloidosis. Circulation. 2016;133(24):2404-12.

16. Dorbala $S$, Ando Y, Bokhari S, Dispenzieri A, Falk RH, Ferrari VA, et al. ASNC/AHA/ASE/EANM/HFSA/ ISA/SCMR/SNMMI expert consensus recommendations for multimodality imaging in cardiac amyloidosis: Part 2 of 2-Diagnostic criteria and appropriate utilization. J Nucl Cardiol. 2019;. https://doi.org/10.1007/s12350-019-01761-5.

17. Kyriakou P, Mouselimis D, Tsarouchas A, Rigopoulos A, Bakogiannis C, Noutsias M, et al. Diagnosis of cardiac amyloidosis: a systematic review on the role of imaging and biomarkers. BMC Cardiovasc Disord. $2018 ; 18(1): 221$.

18. Damy T, Kristen AV, Suhr OB, Maurer MS, PlanteBordeneuve $\mathrm{V}, \mathrm{Yu} \mathrm{CR}$, et al. Transthyretin cardiac amyloidosis in continental Western Europe: an insight through the Transthyretin Amyloidosis Outcomes Survey (THAOS). Eur Heart J. 2019;. https://doi.org/10.1093/eurheartj/ehz173.

19. Czobor P, Hung YY, Baer D, McGlothlin D, Weisshaar D, Zaroff J. Amyloid cardiomyopathy in a large integrated health care system. Am Heart J. 2019;216:42-52.

20. Aus Dem Seipen F, Hein S, Prestel S, Baumgartner C, Schonland S, Hegenbart U, et al. Carpal tunnel syndrome and spinal canal stenosis: harbingers of transthyretin amyloid cardiomyopathy? Clin Res Cardiol. 2019;108:1324-30.

21. Fosbol EL, Rorth R, Leicht BP, Schou M, Maurer MS, Kristensen SL, et al. Association of carpal tunnel syndrome with amyloidosis, heart failure, and 
adverse cardiovascular outcomes. J Am Coll Cardiol. 2019;74(1):15-23.

22. Witteles RM, Bokhari S, Damy T, Elliott PM, Falk $\mathrm{RH}$, Fine NM, et al. Screening for transthyretin amyloid cardiomyopathy in everyday practice. JACC Heart Fail. 2019;7(8):709-16. 